\title{
DISCURSO DE GABRIEL TORTELLA \\ EN EL ACTO DE RECEPCIÓN DEL PREMIO \\ REY JUAN CARLOS DE ECONOMÍA *
}

(5 diciembre 1994)

Majestad, señoras, señores:

He recibido el Premio Rey Juan Carlos de Economia con alegria, con agradecimiento, y con mucha humildad. La alegria y el agradecimiento van mezclados, por la magnitud del galardón, que lleva el nombre del Rey de España, por su cuantía, que se debe a la generosidad de don José Celma Prieto, y por el fundado y general prestigio de mis antecesores. La humildad se debe a la conciencia de las limitaciones de mi persona y de mi obra, que me parecen desmerecer ante los motivos de alegría que acabo de mencionar. Lo único que me consuela en mi confusión ante la posibilidad de recibir un galardón desproporcionado a mis méritos es la reconocida competencia de los miembros del comité que lo ha concedido. «Quizá - me digo en mis momentos de optimismo-, si no se han equivocado, como es evidente, en las ocasiones anteriores, es posible que algún fundamento haya tenido la presente decisión.»

$Y$, efectivamente, creo que el presente premio tiene una cierta justificación, que sólo indirectamente se refiere a mi persona. Se está aqui honrando a alguien que ha trabajado durante ya muchos años en una disciplina de economía aplicada, disciplina que ha tenido un brillante desarrollo en los últimos decenios, tanto en España como en el mundo. Esto fue también reconocido por el comité del Premio Nobel el pasado año, al galardonar con el de Economía a dos historiadores económicos, Robert Fogel y Douglass North. El comité del Premio Rey Juan Carlos ha tenido la generosidad y el acierto de buscar un campo de la economía no teórica donde el conocimiento se está renovando

* Publicado con el amable permiso de la Fundación «José Celma Prieto». 
a gran velocidad, y no se me oculta que estoy entre los más viejos practicantes del ala más «economicista» de la Historia económica. Sólo así puedo entender el honor que se me ha hecho.

Por todo ello, el capitulo de mis agradecimientos debe continuar, después de los ya expresados, por esa generación de colegas, amigos, y discipulos cuyo impresionante trabajo me ha aupado a la altura en que ahora me encuentro. Creo que era Isaac Newton quien decía que, si había visto lejos, era porque había subido al hombro de gigantes. Él se estaba refiriendo a sus antecesores en lo que hoy llamamos la «revolución cientifica» de la Edad Moderna. Yo me veo, paradójicamente, apoyado en los hombros de los más jóvenes, de quienes sin duda he recibido más de lo que yo pudiera haberles dado en el comienzo de sus carreras. A algunos de ellos (por desgracia las limitaciones de tiempo me impiden referirme a todos) citaré más adelante.

También he tenido maestros, y por lo tanto, motivos de agradecimiento a mis mayores. No quiero hacer autobiografia, pero sí expresar algo que ya manifestó aqui Julio Segura hace cuatro años: mi agradecimiento a mis padres por haberse preocupado mucho por mi educación, y por haberme enviado al Colegio «Estudio», donde por cierto también estudió Julio. Allí tuve grandes maestros; voy a mencionar sólo a las tres mujeres excepcionales que dirigian el colegio: Carmen García del Diestro, Ángeles Gasset, y Jimena Menéndez Pidal; y a dos profesores, Miguel Catalán y Antonio Rodríguez Huéscar, sabiendo que cometo una injusticia de omisión forzado por la necesidad de evitar una enumeración excesiva. En «Estudio» recibi una mezcla de formación humanística y curiosidad cientifica que marcaron mi vocación. Mis estudios universitarios, en cambio, fueron una decepción: me licencié en Derecho con desgana. No tengo madera de jurista. Pero allí encontré un profesor, José Maria Naharro, que me abrió los ojos a la Teoría económica. Las magnificas lecciones de $\mathrm{Na}$ harro fueron para mi un verdadero descubrimiento. En medio de lo que me parecía el laberinto desolado de la casuistica jurídica se me ofrecia una teoría convincente de la conducta humana en sociedad. No volvi a encontrar nada tan fascinante en la carrera, y mi afición por la Economía quedó establecida. Dada mi inclinación paralela por la Historia, parecía natural que me convirtiera en historiador económico, y esto lo hice en Estados Unidos, bajo la dirección de Rondo Cameron en la Universidad de Wisconsin. Aún recuerdo cuando, al poco tiempo de conocernos, me preguntó Cameron: «ंTienes tema de tesis?». Al decirle yo que no tenia, pronunció una frase que marcó mi destino: «Harás la historia de la banca española».

$\mathrm{Y}$ mi último agradecimiento de hoy tiene que ser a la institución que nos acoge, el Banco de España, que desde este lado del Atlántico me permitió 
cumplir en la medida de mis posibilidades el encargo de mi maestro norteamericano. Este Banco ha dado muestras de una sagaz visión de las potencialidades de una disciplina científica entonces en embrión en España, y ha prestado un apoyo a la Historia Económica sin el cual el desarrollo de esta ciencia que hoy celebramos habría tenido lugar en una medida mucho menor. La actitud del Banco hacia la investigación, y en concreto hacia la Historia económica, causó un cierto asombro admirativo en círculos académicos internacionales (recuerdo la cara que puso Cameron cuando le expliqué la ayuda que el Banco me prestaba), y hoy su ejemplo es seguido por otros bancos, centrales y privados, hasta el extremo de haberse creado hace cuatro años, con sede en Francfort, una Asociación Europea de Historia Bancaria merced al mecenazgo de un número considerable de bancos públicos y privados. Si el Banco de España es uno de los primeros institutos oficiales del mundo, en su primera encarnación como Banco Nacional de San Carlos, también es uno de los primeros en este apoyo decidido a la investigación en historia económica y bancaria. $Y$ esta comprensión y aliento tienen dos protagonistas principales: Mariano Rubio y Ángel Rojo, que mucho antes de ser gobernadores, desde sus puestos en el Servicio de Estudios del Banco, favorecieron a la Historia económica (y a la Economia en general, por supuesto) con becas y ayudas. No voy a decir más de la impresionante labor científica que este Banco sustenta; algo dijo ya sobre ello aqui hace dos años un mexicano, Miguel Mancera, mi inmediato antecesor en este premio. Sólo quiero mencionar la creación por el Banco de España de una Biblioteca de investigación y de un Archivo Histórico que están a disposición de todos los estudiosos, que no tienen parangón en España y pocos en el mundo, y que son instrumentos básicos para nuestra labor investigadora.

En el tiempo que me queda voy a tratar de sintetizar las principales aportaciones de la Historia económica a las dos grandes disciplinas que la flanquean, la Economía y la Historia. A raíz de la publicación en la prensa de la concesión de esta quinta edición del Premio Rey Juan Carlos, varios periodistas me han preguntado, sin duda haciéndose eco del sentir popular, que para qué sirve la Historia económica. No me ha sido difícil salir del paso comparando a la Economia con la Medicina (trayendo a colación al Dr. François Quesnay, médico de Mme. Pompadour, fundador de la escuela fisiocrática, y precursor de las tablas input-output, que son como una radiografía del cuerpo social o un esquema de la circulación sanguínea de ese cuerpo) y asimilando la 
Historia económica con la historia clínica que todo médico requiere de su paciente. Pero naturalmente las cosas son más complejas.

La Historia económica tiene por objetivo básico estudiar y analizar el éxito (o fracaso) alcanzado por los distintos sistemas económicos en la producción de bienes y servicios destinados a satisfacer las necesidades de consumo del ser humano. Se ocupa, por tanto, de aquellos aspectos de la relación entre el hombre y el medio que tienen que ver con la vida económica, es decir, con la satisfacción de necesidades materiales tales como la provisión de alimentos, vestido, o alojamiento. La Historia económica aplica, pues, los métodos económicos e históricos al estudio del pasado, dando a la denominación «pasado» un sentido lato.

Obsérvese que según la anterior definición la Historia económica es una de las ramas de la Economía aplicada. Ésta seria la opinión de Joseph Schumpeter, para quien la Economía se dividía en tres ramas: la Teoría económica, la Estadística, y la Historia, de las cuales él consideraba a la tercera, la Historia, como la más importante. Hoy cambiariamos algo la terminologia de Schumpeter y hablaríamos de Teoría, Econometría, y Economía aplicada, pero la división tripartita de Schumpeter sigue siendo válida para la mayor parte de los economistas. En un libro editado en 1986 por William Parker acerca de la relación entre Economía e Historia económica, Kenneth Arrow afirma que la Teoría económica es como la Física teórica en el área de las Ciencias Naturales, y la Historia económica es uno de los campos de la Economía aplicada, como la Geología o la Física atómica son Física aplicada. Robert Solow sostiene en ese mismo libro que la relación entre Economía e Historia económica es aún más estrecha. Solow es escéptico acerca de la comparabilidad entre Física teórica y Teoría económica, por la bien conocida razón de que en ciencia social no se puede experimentar, y que además «toda actividad puramente económica está envuelta en una red de instituciones sociales, costumbres, creencias, y actitudes. Los resultados se ven sin duda afectados por estos factores de fondo, de los cuales unos cambian lenta y gradual, y otros erráticamente». Por tanto, concluye Solow, Economia e Historia económica son prácticamente lo mismo. El trabajo del economista está sujeto a las mismas limitaciones y problemas que el del historiador. Y concluye Solow humoristicamente: «un historiador económico es simplemente un economista con alta tolerancia para el polvo». Es decir, un economista aficionado a los archivos.

Don McCloskey, el enfant terrible de la Historia económica, llega a más en ese mismo libro: no es que Economía e Historia económica sean casi lo mismo. Es que las dos, según McCloskey, son ramas de la Historia. Arrow nos dice que Economía e Historia económica, aunque cercanos, son dos campos; 
Solow, que quizá uno y medio. McCloskey dice que son lo mismo. «Puesto que Economia e Historia económica tienen los mismos gustos, tecnologia, y dotación de factores, no tienen nada que comerciar. Económicamente hablando son el mismo país.» Pero además, incluso los teóricos benevolentes que consideran a la Historia económica como un subconjunto de la Economía están equivocados. Es la Economía la que es «un subconjunto de la historia». La Teoría económica y la Física teórica no tienen nada que ver; lo del paralelismo entre las dos es un «cuento» que Paul Samuelson y Milton Friedman se inventaron y que los economistas se han creido porque no saben nada de Física. La Teoría económica no produce leyes, como hace la Física, sino que cuenta historias. ¿Cómo va a producir leyes científicas la Economía si no puede experimentar? Lo que hacen los economistas es contar historias, con muchas matemáticas y estadísticas, pero historias. Los «economistas — nos dice McCloskey - tratan de hacer lo mismo que los historiadores, es decir, contar historias plausibles sobre el pasado. [...] La economía aplicada es la historia económica del pasado reciente». No es que los economistas tengan que aprender de los historiadores. Es que son historiadores.

La postura de McCloskey tiene mucho de provocación. Sin embargo, me parece que Solow y él están más en lo cierto que Arrow. Más precisamente, creo que la postura correcta es la de Solow. Para demostrarlo, en las páginas que siguen voy a tratar de argüir los siguientes puntos: Primero, pese a sus similitudes con la Física teórica, la Teoría económica, como ciencia social que es, se diferencia cualitativamente de ella, y esa diferencia es irreducible. Por lo tanto, sin llegar a las exageraciones de McCloskey, la proximidad entre Teoría económica e Historia es mayor de la que postulan aquellos economistas que creen en el paralelo entre Física teórica y Teoría económica. Segundo, la Historia económica, pese a estar, especialmente en su rama de Economia histórica o «Cliometria», muy cerca de la Economía en general, o de la Economía aplicada, tiene algunos rasgos distintivos que la identifican como ciencia aparte.

Veamos el primer punto. Según Milton Friedman en sus Ensayos de economía positiva, el objetivo final de una ciencia es el desarrollo de una teoría, o una serie de teorias (los modelos a que se refería Solow) que nos proporcionen predicciones válidas. Desde este punto de vista, la validez de una teoría cientifica depende de su poder para predecir el tipo de fenómeno que está destinada a explicar. Para Friedman, el único criterio para aceptar o rechazar una teoría (en Economía como en Física) es contrastarla con la realidad y ver si la predice adecuadamente. Desde este punto de vista, la Teoría económica aplicada a la Historia actuaría como la Física con respecto a las ciencias aplicadas, ya que la predicción puede referirse tanto al pasado como al futuro. 
La Teoria es sin duda una herramienta utilisima al historiador económico. Pero la analogia de Friedman plantea problemas, porque nos encontramos dentro del campo de las ciencias sociales, y aqui hay claras diferencias con muchas de las ciencias físicas. La primera de estas diferencias es la dificultad para llevar a cabo experimentos, a la que se referian como vimos Solow y $\mathrm{McCloskey.} \mathrm{Este} \mathrm{es} \mathrm{un} \mathrm{punto} \mathrm{que} \mathrm{ha} \mathrm{sido} \mathrm{repetidamente} \mathrm{desarrollado} \mathrm{por} \mathrm{mu-}$ chos autores, como Ernst Nagel o Karl Popper, y no voy a insistir en él por lo bien conocido.

A cambio de su falta de experimentalidad, sin embargo, la Teoría económica tiene sobre las ciencias de la naturaleza la ventaja de contar con la introspección como una de sus fuentes. El autor y el actor de la Teoría económica son en gran medida el mismo individuo. Como dice Schumpeter, la Teoria económica tiene «amplio conocimiento del significado de las acciones económicas», a diferencia de la Física, cuyo significado último escapa al estudioso. En palabras de Albert Einstein:

En nuestro esfuerzo por entender la realidad [física] somos en cierto modo como un hombre tratando de entender el mecanismo de un reloj cerrado. Ve la esfera y el movimiento de las manillas, oye el tictac, pero no tiene modo de abrir la caja. Si es ingenioso puede hacerse una imagen del mecanismo que explica las cosas que él observa, pero no puede estar seguro de que su imagen sea la única que explica sus observaciones. Nunca podrá comparar su imagen con el verdadero mecanismo; ni siquiera puede imaginar la posibilidad o significado de tal comparación.

Para el economista esta barrera entre él y el objeto de su estudio no existe. Dados los supuestos básicos de la Teoría económica, ésta puede, de una manera inasequible a las ciencias naturales, completar los resultados de las observaciones con extrapolaciones en cuanto a la conducta de los sujetos económicos. He aqui otra diferencia fundamental entre Teoria económica y Física teórica, con clara ventaja para la Economía. Por esta razón no se puede estar totalmente de acuerdo con la afirmación de Friedman de que una teoria, incluida la Teoría económica, no debe ser juzgada por el realismo de sus supuestos, sino tan sólo por el resultado de sus predicciones. Esta postura de Friedman, que está dirigida a defender la teoria de la concurrencia perfecta de los ataques de que había sido objeto por los partidarios de la teoria de la concurrencia imperfecta o monopolística, intenta establecer un paralelo entre la Ciencia Social y la Física que es, como vemos, excesivo. Friedman pone varios ejemplos para ilustrar sus afirmaciones. Uno de ellos es el del fototropismo de las plantas. Las hojas de los árboles, nos dice, se colocan de modo que la planta en su 
conjunto reciba el máximo de luz solar. Por lo tanto, la posición de cada hoja obedecerá a este principio como si cada una de ellas conociera la posición de las demás, y la trayectoria del sol durante el día. En realidad, nosotros sabemos que esto no es cierto, que las hojas se comportan «como si» supieran, y eso es todo lo que le interesa a la ciencia a la hora de predecir la conformación general de los árboles. Aquí el paralelo económico reside en la teoría de la competencia perfecta: no importa que sean muchos o pocos los concurrentes, que piensen esto o aquéllo acerca de su posición en el mercado; lo importante es que tomen el precio como dado (que sean «precio-aceptantes», price takers), o no.

De este y otros ejemplos Friedman concluye que lo importante para que haya competencia no es que se den las condiciones (prácticamente imposibles) de la concurrencia perfecta, sino que se den sus consecuencias, es decir, que las empresas acepten el precio de equilibrio del mercado. En otras palabras: no importa que un mercado esté dominado por un oligopolio si este oligopolio practica una política de precios equivalente a la que se daría en un mercado de libre concurrencia.

Sin embargo, la cuestión es más complicada en Economía que en Física, precisamente porque en Economía no nos enfrentamos a un reloj cerrado: en Economía podemos tener una idea, por aproximada que ésta sea, de las motivaciones de los actos humanos. Como dice McCloskey, la predicción económica no es como la predicción física, ni siquiera la más común, la predicción meteorológica. En la predicción económica «los frentes fríos escuchan y los propios predictores son parte del clima». Retomando el argumento de Friedman, para éste si el precio de mercado se comporta como nos predice el modelo de libre concurrencia, el modelo queda vindicado, aunque este comportamiento no se deba a que la libre concurrencia se dé en realidad, sino, por ejemplo, a que los oferentes oligopolísticos teman la interferencia del gobierno si suben los precios excesivamente, o a que estén tratando de expulsar a un rival del mercado. En estos casos, el resultado a corto plazo en términos de precio o de cantidad intercambiada puede ser idéntico al de libre concurrencia: a largo plazo, sin embargo, las consecuencias pueden ser totalmente diferentes. Los supuestos de partida y el realismo del modelo, por tanto, son más importantes de lo que Friedman admite.

En conclusión, no puede aceptarse la afirmación de que en ciencia social la única contrastación de una teoría sea la verificación empírica de sus predicciones, y que el realismo en las hipótesis no tenga ninguna importancia, por las dos razones que acabamos de ver. En primer lugar, porque al no ser una ciencia experimental, la Teoría económica no puede someter sus predicciones a 
un escrutinio tan exhaustivo y detallado como puede hacer la Ciencia Física. El número de contrastaciones a que se podrá someter una predicción económica será mucho menor que el que puede hacerse a una teoría física, y la contrastación empírica nunca resultará tan satisfactoria. Si estos resultados no se someten a un escrutinio cuidadoso que incluya un examen del realismo de la teoría, el economista práctico puede caer en el error. En segundo lugar, y en compensación, la ciencia económica tiene a su alcance un medio de contrastación en cuanto al realismo de las hipótesis de que la ciencia natural carece: el conocimiento directo de la naturaleza humana. Por lo tanto, la Teoría económica es una ciencia social, cualitativamente diferente de las ciencias físicas, y estrechamente emparentada con las demás ciencias humanas.

En virtud de todo esto, y entrando ya en el segundo punto de los antes planteados, ¿cuál es la diferencia entre Economía a secas e Historia económica, si es que hay alguna? La respuesta es que si hay diferencias. En primer lugar, hay una o varias ramas de la Historia económica que, más que emparentarse con la Economia, se emparientan con la Historia. Estudian fenómenos económicos, pero apenas utilizan las «herramientas» de la Economia. Al fin y al cabo, como ha observado el tantas veces citado (su agudeza lo merece) McCloskey, «es posible hacer excelente historia económica sabiendo poca economía [... Así, por ejemplo] Moses Finley, el mejor historiador económico del mundo antiguo, y Fernand Braudel, el mejor historiador del mundo moderno, han hecho contribuciones importantes sin saber economia». Y lo mismo podríamos decir, en el caso español, de A. Domínguez Ortiz para la Edad Moderna, y J. Vicens Vives y N. Sánchez-Albornoz para la Contemporánea. Yo no creo en la exclusión científica, y no creo por tanto que ninguna rama de la Historia económica tenga derecho a erigirse en monopolista del título y excluir a las demás. Creo, por el contrario, que la ciencia debe juzgarse por sus resultados, y que todas las ramas y enfoques de nuestra disciplina son válidos mientras alcancen conclusiones interesantes a partir de métodos admisibles científicamente. No respeto por tanto las fronteras cientificas. Sin embargo, en este momento me estoy ocupando del sector más propiamente económico de nuestra disciplina, de la llamada Historia Econométrica, Cliometría, o Economía Histórica. La pregunta que me hago es si esta Historia económica es una rama de la Economía aplicada, si la única diferencia entre un cliómetra y un economista a secas es, simplemente, como diría Solow, que el primero tolera mejor el polvo; o si, como afirma McCloskey, la Economía es la Historia económica del presente (lo cual viene a ser lo mismo).

Mi posición es un sí cualificado, con una fuerte cualificación. La Historia económica es Economia retrospectiva, si, pero en esa retrospección hay un ele- 
mento diferencial muy grande: la Historia económica es la Economía del largo plazo. No es sólo que la Historia económica se remonte más lejos en el pasado, es que estudia periodos más largos. Y la introducción de una perspectiva temporal más larga exige una modificación importante del método económico.

En efecto, como es bien sabido, el recurso metodológico más común en Economia es el del equilibrio parcial marshalliano, consistente en concentrar la atención en un mercado, unidad, empresa, lo que sea, y suponer que el resto de la economía no cambia, o cambia sólo en aquellos aspectos que a nosotros nos interesa estudiar. En realidad, el del equilibrio parcial es un recurso científico que aproxima el economista al científico físico, ya que tiene muchas de las características del experimento. Se trata de un experimento mental (aunque hoy, con los métodos de simulación, se haga con la ayuda de ordenadores), como los físicos, Einstein especialmente, hacían y hacen. Ahora bien, el sistema del equilibrio parcial exige el conocido supuesto caeteris paribus («todo lo demás constante»), y ese supuesto requiere tomar un lapso temporal de estudio muy corto, porque a largo plazo todo cambia. Y ésta es la gran diferencia entre el historiador económico y el economista a secas. El historiador económico debe ser muy cuidadoso con el modelo de equilibrio parcial, porque el supuesto caeteris paribus es de problemática aplicación a largo plazo. A largo plazo cambian todos aquellos elementos que el economista acostumbra a tomar como constantes: los gustos, las instituciones, hasta la estructura de la población. Y el historiador, por tanto, debe tener en cuenta esta gran limitación en su utilización de los modelos económicos, que generalmente son de equilibrio parcial. Por eso, a la pregunta de Charles Kindleberger de si la Economía histórica es arte o ciencia diríamos que toda ciencia social incluye elementos de ambas disciplinas, incluso la Economía, que es la que más puramente cientifica se presume. Y que la Historia económica, o la Economía histórica, comporta una proporción mayor de arte que la Economia, porque debe combinar un número mayor de elementos y variables, y debe depender más del juicio intuitivo para decidir qué modelos son aplicables y con qué limitaciones.

¿Y qué ocurre con el equilibrio general walrasiano?, se preguntarán ustedes. También en economía se utilizan modelos de equilibrio general, aunque pocos de ellos tienen la operatividad de los de equilibrio parcial. Pues en realidad ocurre algo muy parecido, porque los modelos operativos que tenemos de equilibrio general, los modelos de tipo Quesnay-Walras-Leontief (input-output, programación lineal) son característicamente instantáneos: nos permiten hacer ejercicios de estática comparativa, pero no escribir historia hacia atrás, como pretendiera hace años Jeffrey Williamson.

El historiador económico, por tanto, y haga lo que haga, está más cerca del 
historiador tradicional a secas porque tiene que emplear una mayor cantidad de intuición que el economista del corto plazo, aunque sólo sea para justificar la aplicación al largo plazo de modelos que fueron construidos pensando en la validez del supuesto caeteris paribus. $\mathrm{Y}$ también porque el número de variables que debe tener en cuenta es mucho mayor. Por algo decía John Hicks:

Una función importante de la historia económica, me parece a mi, es ser un foro donde pueden encontrarse y conversar los economistas con los politólogos, los juristas, los sociólogos, y los historiadores - historiadores de hechos, de ideas y de tecnologias.

La razón, creo yo, de que la Historia económica sea el punto de encuentro de todos estos especialistas es que, al no darse el supuesto caeteris paribus a largo plazo, todas las variables de esas otras ciencias que el economista a secas puede esconder bajo la alfombra deben ser tenidas en cuenta por el historiador económico. Esto no nos simplifica la tarea; al contrario, nos la complica. Pero también hace que nuestra disciplina sea la más apasionante de las ciencias sociales.

La Teoría económica es sin duda el edificio más imponente de que disponen estas ciencias, edificio construido por generaciones de investigadores sobre los cimientos trazados por las escuelas anteriores al gran fundador, Adam Smith, y, por supuesto, por éste mismo. Todos los economistas admitimos la primacía de la Teoría, que constituye algo así como nuestro cuartel general o nuestro templo, y también, para repetir la expresión feliz de Joan Robinson, nuestra caja de herramientas. Ahora bien, ese templo no está terminado, como han demostrado abundantemente mis antecesores en este premio, y esa panoplia de herramientas se renueva constantemente. Se necesita una cantera para allegar los materiales que permitan seguir construyendo el templo y probando las herramientas, y la más vasta cantera de materiales para la construcción teórica la proporciona la Historia. La Historia es, en realidad, además de fuente de materiales, el banco de pruebas y el juez último de la Teoría económica, el que determina qué pabellones o alas del majestuoso edificio deben subsistir o ser demolidos, el que selecciona o descarta las herramientas teóricas a utilizar; la Historia es, en una palabra, el campo de experimentación de esa gran ciencia social que es la Economia. 
Por esta razón la mayor parte de las discusiones entre economistas acaban refiriéndose a la historia, y por esta razón el fundador de la economía científica, Adam Smith, llenó su La Riqueza de las Naciones de ejemplos y casos históricos, demostrando su vasta erudición de historiador al par que su genio como economista. No me resisto a traer a colación el primer ejemplo del método deductivo-inductivo de Smith, que se manifiesta en el celebrado Capítulo III de La Riqueza de las Naciones, bajo el título «La división del trabajo está limitada por la extensión del mercadom. Este título enuncia uno de los teoremas fundamentales del libro, y Smith lo demuestra del siguiente modo. Los oficios muy especializados se desarrollan en las grandes ciudades, mientras que en las comunidades aisladas los artesanos tienen que trabajar en actividades muy diversas. Yo propondría como ejemplo claro de este principio el de la profesión médica: un médico rural tiene que ser generalista, mientras que en Madrid o en Nueva York puede haber grados de especialización facultativa que llegan a extremos sorprendentes. Pero el mercado no requiere una aglomeración física: si el transporte es lo suficientemente barato, el mercado puede estar compuesto por comunidades distantes unidas por una red comercial. La especialización, y con ella el progreso económico, se verán muy favorecidos por las condiciones de transporte. El agua es un medio ideal para el acarreo masivo de mercancías: por lo tanto esperaremos que las comunidades se desarrollen económicamente junto a las vías navegables. Pues bien, la historia muestra que esto ha sido asi. Y dice Smith textualmente «Las naciones que, según la historia mejor autenticada, parecen haber constituido las primeras civilizaciones, son aquéllas que se instalaron en las costas del mar Mediterráneom; y continúa explicando, de una manera un tanto pintoresca, que el Mediterráneo constituye una excelente vía de transporte. En definitiva, desde el comienzo de su libro Smith busca en la Historia la confirmación de sus teorías. Y esto es lo que hacen, más o menos explícitamente, todos sus seguidores: el propio Ricardo, cuya obra está considerada modelo de razonamiento deductivo, acude a la historia de las colonias norteamericanas para contrastar su teoria de la renta de la tierra.

Acercándonos más a nuestros días quiero citar algunos ejemplos, de entre los muchos que podrian aducirse, de esta íntima conexión entre Teoría e Historia económicas. Uno de los pilares de la nueva teoría macroeconómica que se puso en práctica la pasada década, el llamado «Monetarismo», se basa en una reciente reformulación de la vieja «Teoria Cuantitativa», que relaciona la evolución del nivel general de precios con la cantidad de dinero en circulación. Se trata de la formulación de Milton Friedman, de que nos habló elocuentemente Ángel Rojo en este foro en 1986. La versión friedmaniana de la 
teoría cuantitativa trata de contrarrestar la formulación dominante anterior, la de John Maynard Keynes, que estaba en gran parte basada en los escritos de Earl Hamilton sobre la evolución de los precios en la España del siglo XVI. Para refutar la versión keynesiana, Friedman, en colaboración con Anna Schwartz, publicó hace 31 años una impresionante historia monetaria de los Estados Unidos, que hoy permanece virtualmente vigente. No voy a entrar aqui en los relativos méritos de ambas teorías. Ángel Rojo lo hizo magistralmente entonces. Lo que quiero subrayar es que cuando dos grandes economistas del siglo XX se enfrentan (aunque sea diacrónicamente) recurren a la Historia económica para basar sus afirmaciones. (Entre paréntesis quiero señalar que no siempre que los economistas recurren a la Historia lo hacen acertadamente. Ni Hamilton ni Keynes interpretaron correctamente, en mi opinión, las causas y las consecuencias de la llamada «Revolución de los precios» del siglo Xvi. Y la apelación que hace Keynes en algún pasaje de su Teoría General a las pirámides de Egipto y a las catedrales medievales como antecedentes de la política del «multiplicador» keynesiana, parecen más rasgos de humor que contribuciones sólidas al conocimiento.)

Estamos en el Banco central español, el banco más antiguo de la nación y uno de los más venerables de Europa. Quien está en el uso de la palabra ha vertido mucha tinta escribiendo sobre bancos. Algo debe decir sobre la relación entre Teoría e Historia bancarias. La teoría bancaria ha evolucionado en estrecha relación con la labor de los historiadores. Si la comprensión de la función de los bancos centrales y su papel como reguladores de la Oferta Monetaria se ha visto reforzada recientemente por las incursiones históricas de Friedman, la teoria sobre el papel de los bancos en el desarrollo, propuesta por Schumpeter a principios del presente siglo, se ha visto reforzada y modificada por los estudios de Alexander Gerschenkron, Raymond Goldsmith, Rondo Cameron, David Landes, y Maurice Lévi-Leboyer, por mencionar sólo a los más conocidos. Sus trabajos han mostrado la corrección esencial de las intuiciones schumpeterianas, aunque sin duda han añadido notables refinamientos y cualificaciones. La más importante aportación de los historiadores es sin duda el énfasis que han puesto en las diferencias existentes entre distintos sistemas institucionales y estructuras bancarias, y las consecuencias que esas disparidades tienen sobre la efectividad de unos y otros sistemas y estructuras como instrumentos de desarrollo. La historia ha demostrado que los sistemas bancarios difieren de unos países a otros. Esto no parece muy importante ni profundo. Sin embargo, lo que sí parece importante es que, de un lado, estas diferencias pueden explicarse en términos de estructuras económicas, determinantes históricos, y grados de desarrollo; y que, de otro, tales discrepancias pueden 
medirse, facilitando la comparación. Y más importante aún es que estas divergencias expliquen parte del diferente éxito de los paises en su proceso de desarrollo, lo cual permite formular recomendaciones de política económica. No hay duda, por ejemplo, de que los trabajos de estos historiadores, mostrando el buen funcionamiento de los sistemas bancarios poco intervenidos, han contribuido al reciente movimiento de desregulación al que se refería hace dos años Miguel Mancera. Más adelante veremos que el caso español se encuadra perfectamente en la visión schumpeteriana del desarrollo económico.

La «convergencia económica», es decir, el hecho de que las economías adelantadas tiendan a crecer más despacio que las atrasadas, es un hecho observable que saltó a las páginas de las revistas académicas hace una década, especialmente a partir de un célebre artículo de William Baumol. Poco después la idea fue transferida a la esfera de la política internacional, y de ahí a la prensa diaria, de modo que desde hace unos años raro es el día en que no se nos bombardea con la dichosa expresión. La cuestión tiene cierto interés teórico: de un lado está el hecho (casi de puro sentido común) de que ningún ente puede crecer a tasas constantes durante largos períodos de tiempo, porque de hacerlo asi se saldría de su hábitat natural. La convergencia, en el sentido de que a la larga las tasas de crecimiento decrecen, parece asi algo matemática o biológicamente necesario. Otra cuestión es la explicación económica de la convergencia, y su evidencia empírica. Respecto a esta última, son los historiadores económicos con gran capacidad y vocación para el manejo de grandes bancos de datos los que habían ya puesto de relieve el hecho de la convergencia, basándose en la labor titánica de Simon Kuznets. Me refiero a investigadores como Paul Bairoch, Angus Maddison, Nick Crafts y, en España, Leandro Prados de la Escosura. Más adelante veremos también qué tiene que decir la teoría de la convergencia sobre la historia de España. En cuanto a la razón económica de la convergencia, fue Alexander Gerschenkron, basándose en ideas esbozadas anteriormente por Colin Clark, Kuznets, y aún anteriormente por los grandes clásicos tales como Marx, Ricardo, y Smith, quien construyó su modelo verbal del atraso relativo basándolo en los mecanismos que han favorecido la convergencia histórica. Por decirlo muy brevemente, se trata de la ventaja del recién llegado, que puede adoptar las últimas innovaciones, sin estorbos tales como los viejos hábitos, las inercias institucionales y los intereses creados; y que para ello puede movilizar medios e instrumentos que su condición de rezagado le permite, desde ideologías nacionalistas y utópicas hasta una política de fuerte intervención estatal. Para un historiador económico, por tanto, esta gran 
novedad de la convergencia es algo muy familiar: vino viejo en odres nuevos. Una vez más, los economistas han descubierto la Historia.

Quiero concluir refiriéndome a las contribuciones de la Historia económica a la Historia sin calificativos. Pero tal contribución es tan vasta y tan variada que no me parece necesario ni posible traerla aquí a colación con alguna pretensión de sistematicidad. Me referiré a un par de cuestiones generales que me parecen muy significativas, y terminaré con una breve referencia a lo que la Historia económica ha hecho por la Historia de España. Las cuestiones generales son, en primer lugar, la llamada «interpretación económica de la Historia»; $y$, en segundo lugar, un artefacto relativamente reciente: el «modelo contrafactual».

Aunque es tema muy discutido en cuanto a la magnitud de su alcance, la importancia de la Economia para comprender el desarrollo social en el presente y en el pasado me parece algo generalmente admitido. Baste indicar que los estudios sobre la Revolución industrial, por ejemplo, o sobre la Revolución comercial que la precedió, han mostrado que no se puede comprender cabalmente una sociedad en un espacio geográfico y temporal determinado sin comprender la organización económica que la sustenta. Que son fenómenos económicos como las citadas revoluciones comercial e industrial, en los siglos XVII y XVIII, las que permiten la aparición de las modernas sociedades democráticas de los siglos XIX y $\mathrm{xX}$ me parece un hecho tan evidente que no vale la pena continuar hablando de él. Que la historia de la España contemporánea no se comprende sin un fundado conocimiento de su Historia económica es algo que he tratado de argüir en mi último libro. En mi opinión, las tan traídas y llevadas afirmaciones de Karl Marx sobre la importancia que la economía tiene en las demás parcelas de la actividad social, están hoy aceptadas por la gran mayoría de los estudiosos y los políticos, hasta el extremo de que muchos las admiten sin conocer su filiación ideológica. Como dice Schumpeter, «la interpretación económica de la historia [...] si la reducimos al papel de hipótesis de trabajo y la formulamos cuidadosamente, despojándola de toda la ambición filosófica sugerida por las expresiones Materialismo Histórico o Determinismo Histórico, [resulta ser] un poderoso avance analiticon. Yo creo que ésta es la hipótesis que casi todos los historiadores económicos y un número considerable de historiadores a secas tienen en mente cuando estudian temas económicos (por no hablar, naturalmente, de los economistas). Y esta hipótesis pone de manifiesto una contribución, la más importante, de la Historia económica a la Historia. 
Creo que lo anterior no tiene mucha discusión. Quiero mencionar aquí otra contribución importante, aunque muy controvertida, de la Historia económica a la Historia. Ésta es reciente, de carácter metodológico, y de fácil atribución: la introdujo Robert Fogel a mediados de los años Sesenta, y se llama el contrafactual. El nombre espanta un poco, y su naturaleza ha escandalizado a muchos historiadores tradicionales. Sin embargo, el contrafactual es simplemente el reconocimiento explícito de una práctica muy común del oficio de historiador, consistente en hacer algo asi como un experimento mental para establecer una relación de causa a efecto. En general, la única manera de establecer una relación de causa a efecto es demostrar que cuando no se da la causa no se da el efecto. En las ciencias experimentales esto puede zanjarse sencillamente por medio de experimentos. En las no experimentales el experimento ha de ser imaginario: con ayuda de una teoría hemos de reconstruir hipotéticamente lo que hubiera ocurrido de no haberse dado la pretendida causa. Esto es lo que, de manera más o menos consciente, han venido haciendo los practicantes de la «historia razonada» desde Heródoto hasta hoy. Los historiadores y el hombre de la calle lo hacen implícitamente todos los días; hacen contrafactuales como el Monsieur Jourdain de Molière hablaba en prosa: sin saberlo. El esfuerzo de rigor metodológico realizado por los cliómetras como Fogel les ha llevado a hacer explícito este modo de razonar.

Pongamos un ejemplo de contrafactual: Jaume Vicens Vives y su discípulo Josep Fontana han afirmado que la pérdida del imperio colonial español fue un gran obstáculo al crecimiento económico en el siglo xIx. Prados de la Escosura puso tal afirmación en tela de juicio y para ello trató de estimar cuál fue la magnitud de la pérdida en términos de renta nacional debida a la cesación del tráfico colonial, la pérdida de impuestos, etcétera. Su conclusión fue que en total el fin del Imperio representó para España una pérdida inferior al 6,7 por 100 de la renta nacional. Esta pérdida, considerable pero no devastadora a corto plazo, se vio compensada a largo plazo por una reasignación de recursos que a la larga benefició a la economía española. Construyendo así un modelo razonable de lo que hubiera ocurrido a nuestra economía de haber sobrevivido el Imperio, Prados de la Escosura podía contrastar y desechar una de las hipótesis sobre las causas del atraso español en el siglo XIX.

Se ha objetado que tal propuesta metodológica crea una disciplina sumida en conjeturas y abocada a la ficción irresponsable. El peligro existe, indudablemente; no todas las hipótesis pueden someterse a estos contrastes imaginarios. Tiene sentido preguntarse qué hubiera ocurrido si el Imperio español en América no hubiera sucumbido en 1824 , o si no se hubiera inventado el ferrocarril en el siglo XIX, para tratar de evaluar la trascendencia de tales hechos; no lo 
tiene plantearse la posibilidad de que que no se hubiera descubierto América, o de que no se hubiera dado la Revolución industrial: el alcance de tales acontecimientos es demasiado universal, y su importancia no se discute. Pero los detractores deben admitir que, en ausencia de «modelos contrafactuales» razonables, la Historia quedaría reducida a una triste enumeración de hechos establecidos sin ninguna concatenación causal ni utilidad explicativa. Esta importante innovación metodológica, que se irá imponiendo gradualmente entre los historiadores, es una contribución fundamental de la Historia económica al método histórico.

Volvamos ahora a la Historia de la España contemporánea y tratemos de esbozar brevemente cómo ha contribuido el enfoque «economicista» a mejorar su comprensión. Hace unos cuarenta años la versión más o menos oficial de la Historia de España era cuando menos incongruente. Se nos presentaba un pasado de gloria y esplendor, y un presente empequeñecido. Cómo se había efectuado tal transición no se comprendía cabalmente: la responsabilidad la compartían una serie confusa de coaliciones o conjuras internacionales (casi siempre encabezadas por «la pérfida Albión», que, entre muchas otras perfidias, causó la pérdida del Imperio colonial) y los errores internos, atribuibles esencialmente al «liberalismo decimonónico». Incluso para los mejores historiadores del momento la pérdida del Imperio supuso, como hemos visto, un gran lastre económico y los errores del liberalismo fueron indudables. Se cifraban estos errores, en concreto, en una política económica librecambista, que habría impedido el desarrollo de la industria, y en una desamortización miope que no habría resuelto los problemas agrarios y habría acentuado las desigualdades sociales. El enorme desconocimiento de la realidad económica hacía que unos historiadores vieran en el desarrollo de la industria algodonera catalana una Revolución industrial comparable a la inglesa (lo cual hacía incomprensible los bajos niveles de renta a principios del siglo $\mathrm{xx}$ ), mientras otros creian que el desarrollo económico español había comenzado con el arancel proteccionista de Cánovas en 1892. El siglo XX apenas se consideraba historiable, pero se daba por supuesto que la guerra civil habia sido consecuencia de la extrema pobreza del pais, lo cual, por implicación, significaba que el crecimiento económico era un fenómeno iniciado en la segunda mitad del siglo $\mathrm{xx}$ y por tanto atribuible al intervencionismo extremo del régimen de Franco.

Fruto de este desconocimiento de la economia, la historia política nos mostraba una sucesión de acontecimientos deplorables e incomprensibles: levantamientos, pronunciamientos, motines, guerras civiles, derrocamientos, restauraciones, dictaduras, para terminar en una casi milagrosa transición a la democracia de la que disfrutamos en los últimos decenios. 
Aunque todavia queda mucho por hacer, creo que los historiadores económicos han aclarado bastante este confuso panorama retrospectivo. Gracias a los esfuerzos de reconstrucción macroeconómica de Prados de la Escosura y Albert Carreras, hoy sabemos que hay mayor continuidad en la Historia de la España contemporánea de lo que un repaso superficial a los altibajos de la política pudiera hacer creer. A grandes trazos, nuestra renta por habitante ha evolucionado siguiendo el patrón europeo, especialmente el patrón de los países de la Europa del Sur. Hemos crecido desde principios del siglo XIX, aunque a tasas más bajas que las de los países nórdicos, de modo que, a pesar de ese crecimiento indudable, relativamente nos quedamos atrasados. En el siglo xx nuestro crecimiento fue más vigoroso. La guerra civil no fue debida a la pobreza absoluta sino, en la medida en que cosas tan horribles pueden explicarse, a los traumas y tensiones del crecimiento rápido en las tres décadas anteriores (algo por otra parte común a la experiencia de otros países: las revoluciones inglesa, francesa, y rusa, por poner ejemplos bien conocidos, estallaron tras períodos de fuerte crecimiento económico). Y el desarrollo espectacular de la segunda mitad del siglo XX no parece tan impresionante si se lo compara con la experiencia europea coetánea o con la experiencia nuestra en las tres primeras décadas del siglo xx. Lo que sí es impresionante y casi único en la Historia económica de Europa es el tremendo parón que experimenta la renta española desde 1935 hasta 1954, como observara hace unos 35 años Jacint Ros Hombravella. Que este hiato larguísimo no se debió a los destrozos de la guerra lo prueba el que países como Italia, Francia, o incluso Alemania, más dañados por la guerra mundial, se recuperaran en tres o cuatro años, mientras que a nosotros esa recuperación nos costó más de una década. Este hecho, entre otras cosas, arroja fuertes dudas sobre las virtudes del intervencionismo autárquico.

La convergencia española, por tanto, es un fenómeno del siglo $\mathrm{xx}$, algo que también observamos, con las inevitables salvedades, en las economías italiana y portuguesa, con las que tanto tenemos de común en geografía y en historia. El caso español encaja, en consecuencia, dentro de uno de los patrones regionales europeos, el de lo que se ha dado en llamar el «patrón latino».

Hoy sabemos también que el liberalismo arancelario no fue ni tan intenso ni tan perjudicial como pretendian sus adversarios. Al contrario, la obra de Prados de la Escosura y de Antonio Tena tiende a probar exactamente lo contrario: las épocas de mayor crecimiento económico tienden a coincidir con las de menor proteccionismo arancelario. El libro de Pedro Fraile sobre la industria siderúrgica ha mostrado cómo el exceso de protección puede limitar el potencial de desarrollo de la industria supuestamente protegida, y la tesis de Sebastián Coll sobre la protección al sector carbonifero sugiere algo parecido: la 
utilización del carbón como fuente energética se vio frenada por la excesiva protección (algo que ya habian sugerido los trabajos de Jordi Nadal, Jordi Maluquer de Motes, Carles Sudrià, y Albert Carreras). Siguiendo un enfoque diferente, la labor precursora de Román Perpiñá y un reciente estudio de Jordi Palafox tratan de estimar los costes de la protección desde un esbozo de modelo de equilibrio general referido a la España de los años Treinta, y arguyen que este coste fue considerable.

En cuanto a la desamortización, a la que también se atribuyeron fieros males, las cosas son más complejas de como nos las pintaban. Quizá el trabajo más original sobre el tema sea el de Richard Herr, modelo de labor microhistórica que ha mostrado, de un lado, que la desamortización no es un fenómeno exclusivamente español, sino general europeo - y yo recordaría que también hispanoamericano-; y de otro, que la desamortización no modificó grandemente la distribución de la propiedad, sino más bien perpetuó la situación existente. En otras palabras, la desamortización no explica, como creían los historiadores anteriores, las peculiaridades de la agricultura española. Éstas se encuentran más bien en las condiciones físicas del suelo y en la herencia histórica secular que ha determinado la distribución de la propiedad desde tiempos medievales.

Podemos concluir, por tanto, que la explicación del lento crecimiento del siglo XIX no está en el liberalismo decimonónico, sino probablemente en un excesivo intervencionismo, que impidió que la economía española se beneficiara plenamente de las relaciones económicas con el exterior, en un arcaísmo fiscal que causó un déficit crónico y un crecimiento desmesurado de la deuda pública, y en un arbitrismo financiero que trató de uncir el incipiente sistema bancario al yugo de las necesidades presupuestarias y a grandiosos pero mal meditados planes de obras públicas, al tiempo que se descuidaban sectores tan importantes como la sanidad y la educación, fundamentales para la formación del tipo de capital que hoy sabemos ser el más importante: el capital humano.

Los errores y problemas de un excesivo intervencionismo en el siglo $\mathrm{xx}$ han sido estudiados magistralmente por Manuel Jesús González en un libro ya clásico, y por Carlos Barciela en una excelente monografía publicada por el Banco de España sobre la política agraria después de la guerra civil. La lentitud e imperfección en el desarrollo de nuestro sistema fiscal han sido caracterizadas por Francisco Comin en su monumental tesis, que le valió hace unos años el Premio Nacional de Historia, y que seguía líneas de investigación adelantadas hace decenios por Enrique Fuentes Quintana. Los problemas de un sistema bancario excesivamente tutelado han sido sacados a la luz por Pedro Tedde de Lorca, Rafael Anes Álvarez, y Pablo Martín Aceña (yo mismo hice 
también algún ensayo sobre el tema bajo la inspiración de Rondo Cameron). El caso de la banca española parece encajar perfectamente en el modelo schumpeteriano reformulado por Gerschenkron: en un país atrasado en vías de crecimiento el sistema bancario asume papeles que exceden el puramente comercial, con intervención directa en la inversión industrial y de infraestructura. En el caso nuestro, la peculiaridad del sistema monetario, que fue fiduciario cuando en el resto del mundo triunfaba el patrón oro, permitió una compleja y original relación de la gran banca con el Banco de España que prestó solidez al sistema de banca mixta, sistema que lleva aparejados indudables riesgos, como se puso de manifiesto en Alemania, Austria e Italia durante la Gran Depresión de los Años Treinta.

Por lo que respecta al capital humano, el descuido en que se mantuvieron las cuestiones de sanidad pública hasta bien entrado el siglo xx ha sido destacado en especial por Vicente Pérez Moreda; y los bajos niveles educativos y su relación con el subdesarrollo, con especial atención a la importancia del desfase en la educación femenina, han sido estudiados por Clara Eugenia Núñez. El factor empresarial está recibiendo creciente atención, gracias a estudios precursores como el de Mercedes Cabrera sobre la patronal en la Segunda República y el de Guillermo Gortázar sobre un aspecto hasta entonces inédito de la personalidad de Alfonso XIII: el de inversor. Este estudio sugiere que el Monarca fuera protagonista de una importante mutación en las actitudes económicas de la nobleza española de comienzos de siglo, crecientemente encaminadas hacia la moderna actividad empresarial. Justo es reconocer que ya Vicens Vives habia prestado atención al problema empresarial en su magistral historia de Cataluña en el siglo XIX, publicada en catalán en 1958.

En resumen, nuestra visión de la Historia de España contemporánea es hoy mucho más satisfactoria que hace una generación. No sólo conocemos mejor su economía, sino que entendemos mejor sus perfiles políticos. Sabemos que las convulsiones institucionales y las guerras civiles fueron en el siglo XIX debidas al estancamiento y en el siglo xx al crecimiento. Podemos confiar en la estabilidad de nuestras presentes instituciones porque están basadas en unos niveles de renta y de riqueza sin precedentes en nuestra Historia, y sabemos que la madurez económica trae consigo la madurez política. Conocemos mejor los obstáculos que hubo que vencer en el proceso de desarrollo, y eso nos facilita la identificación de los que aún subsisten.

Sabemos entre otras cosas que el liberalismo económico no pecó por exceso, sino por defecto. Algunos de mis ilustres antecesores en este Premio, como Andreu Mas y Julio Segura, han expuesto las dudas que una parte considerable de los economistas teóricos tienen acerca del modelo neoclásico sobre el 
funcionamiento del mercado. Se ha puesto de relieve en especial que los supuestos que este modelo requiere para que el mercado de competencia perfecta alcance el óptimo paretiano (que por otra parte tiene una deseabilidad limitada y discutible) son de hecho muy poco realistas (así ocurre con la transparencia del mercado, con la divisibilidad de las mercancías, con el número infinito y el tamaño homogéneo de los agentes económicos, etcétera); y se ha señalado también que en la toma de decisiones colectivas pueden ocurrir serias interferencias en el camino al óptimo, aún en condiciones cercanas a la concurrencia perfecta. Esto ha sido demostrado en términos abstractos por Kenneth Arrow y en términos históricos, concretos, por Paul David con su celebrado ejemplo de cómo la configuración del teclado de la máquina de escribir (hoy extendido a los ordenadores), que es técnicamente inferior a varias posibles alternativas, se impuso por simple inercia empresarial, alcanzándose asi un equilibrio que puede ser paretiano, pero que sin duda no es un óptimo absoluto.

Las limitaciones, posibles o reales, del mercado como sistema de organización económica son indudables. Pero la Historia tiene algo muy importante que decir al respecto. $\mathrm{Y}$ esto es que el mercado en el terreno económico, como la democracia en el terreno político, tiene sin duda grandes defectos y produce a menudo resultados no deseables; pero, con todo, es muy superior a las alternativas que hasta ahora se han ofrecido. Ya lo manifestó así aquí Miguel Mancera hace dos años, y no puedo sino concurrir.

Decía John Kenneth Galbraith en la introducción de su obra La sociedad opulenta que, según las leyes de la Física, el abejorro no podia volar por ser demasiado su peso para el tamaño de sus alas. Sin embargo, el animal vuela. Algo así, añadia Galbraith, le ocurre al capitalismo de mercado. En contra de las criticas a menudo razonables de sus detractores, y del hecho de que no se den los supuestos neoclásicos, el sistema funciona. Esto es evidente para cualquier historiador minimamente informado. El propio Karl Marx describió con admiración, en ese panfleto pretendidamente disolvente que es El Manifiesto Comunista, el crecimiento económico sin precedentes que el sistema capitalista había producido desde mediados del siglo XvIII hasta mediados del XIX. Como dicen que dijera en voz baja Galileo Galilei acerca de la órbita terrestre, que los inquisidores le obligaban a negar públicamente, eppur' si muove: sin embargo, se mueve. Lo mismo ocurre con la economia de mercado: a pesar de todo, se mueve. La Historia lo demuestra. 